\title{
ĐỔI MỚI NỘI DUNG VÀ PHƯƠNG PHÁP GIẢNG DẠY MÔN HỌC KẾ TOÁN TÀI CHÍNH TẠI CÁC TRƯÒnG ĐAI HOQC VIẸT NAM TRONG XU THẾ HộI NHẬP QUỐC TẾ
}

\author{
HUỲNH TẤN DŨNG, CỒ THỊ THANH HƯONG \\ Khoa Kế toán - Kiểm toán, Truờng Đại học Công nghiệp thành phố Hồ Chi Minh; \\ huynhtandung_kt@iuh.edu.vn
}

Tóm tắt. Kế toán nói chung và Kế toán tài chính nói riêng là môn học bắt buộc trong chương trình đào tạo ngành Kế toán tại các trường đại học Việt Nam nhằm cung cấp cho sinh viên những kiến thức chuyên sâu trong lĩnh vực kế toán tài chính và những kỹ năng hành nghề kế toán trong tương lai. Trong xu thế hội nhập quốc tế về kinh tế và giáo dục ngày càng sâu rộng, đòi hỏi sinh viên tốt nghiệp ngành Kế toán cần đạt được các kiến thức chuyên môn về kế toán để đáp ứng được nhu cầu của các tổ chức trong và ngoài nước. Điều này đặt ra một thách thức cho các trường đại học Việt Nam trong việc đổi mới nội dung và phương pháp giảng dạy môn học kế toán tài chính, nhất là khi đa số các ý kiến tại buổi Hội thảo "IFRS Định hướng và lộ trình áp dụng tại Việt Nam" do Bộ tài chính tổ chức đều nhất trí lộ trình áp dụng Chuẩn mực Báo cáo tài chính quốc tế tại Việt Nam sẽ bắt đầu từ năm 2020.

Trong phạm vi bài viết này, tác giả trình bày thực trạng giảng dạy môn học Kế toán tài chính tại các trường đại học Việt Nam hiện nay và đưa ra một số giải pháp đổi mới nội dung và phương pháp giảng dạy môn học này nhằm nâng cao chất lượng đào tạo môn học Kế toán tài chính cho sinh viên ngành Kế toán trong xu thế hội nhập quốc tế.

Từ khoá. Đổi mới, phương pháp giảng dạy, Kế toán tài chính, hội nhập quốc tế.

\section{INNOVATING CONTENT AND METHODOLOGY OF FINANCIAL ACCOUNTING EDUCATION IN VIETNAMESE UNIVERSITIES FOR MEETING INTERNATIONAL INTEGRATION}

\begin{abstract}
Financial accounting is a compulsory subject in the curriculum of accounting at the Vietnamese universities. This subject provides students financial accounting knowledge and the accounting practicing skills in the future. In the trend of international integration, accounting graduates have to achieve learning outcomes of knowledge, skills and attitudes in order to satisfy the domestic and foreign organizations. This poses a challenge for Vietnamese universities in the renewal of content and teaching methods of financial accounting courses, especially when the majority of the comments at a seminar on "IFRS - Orientation and roadmap for application in Vietnam "organized by the Ministry of finance agreed with the roadmap for International Financial Reporting Standards applicaton in Vietnam from 2020.

The paper presents the current status of financial accounting teaching at the Vietnamese universities and solutions in innovating content and teaching methods in order to improve the education quality of accounting students in the trend of international integration.
\end{abstract}

Key words. Innovation, teaching method, financial accounting, international integration

\section{GIỚI THIỆU}

Kế toán là một nghề không thể thiếu trong bất kỳ nền kinh tế nào, dựa trên lịch sử phát triển kế toán, kế toán có từ rất lâu đời và bút toán kép xuất hiện ở Venice 1492 (Frederick D.S. Choi, et al), cùng với sự phát triển của các nền kinh tế, Kế toán cũng phát triển, hoàn thiện và có những yêu cầu ngày càng cao. Ngày nay với xu thế toàn cầu hoá và hội nhập kinh tế, kế toán ngày càng đóng vai trò quan trọng trong việc cung cấp thông tin cho người sử dụng trong việc điều hành và ra quyết định, đặc biệt là trong các tập đoàn, các công ty đa quốc gia. Thêm vào đó sự toàn cầu hoá về giáo dục và sự dịch chuyển lao động trong ngành kế toán, 
dịch vụ liên quan đến kế toán giữa các quốc gia trong khu vực cũng đặt ra vấn đề về đào tạo kế toán như thế nào để vừa phải đáp ứng được yêu cầu của xã hội vừa phải cạnh tranh được với các nước trong khu vực.

Hiện nay, cả nước có hơn 90 trường đại học công lập và ngoài công lập có đào tạo ngành kế toán, trong đó môn Kế toán tài chính là môn học chuyên ngành bắt buộc trong chương trình đào tạo. Ở các trường đại học, môn học này được chia thành nhiều học phần (từ 3 đến 4 học phần), mỗi học phần trung bình từ 2 đến 3 tín chỉ. Tuỳ thuộc vào định hướng đào tạo của mỗi trường là hàn lâm hay ứng dụng mà môn học này được đào tạo theo hướng lý thuyết hoặc tích hợp (cả lý thuyết và thực hành). Thực tế cho thấy, ở nhiều tổ chức đạo tạo kế toán, nội dung môn học kế toán tài chính chủ yếu được biên soạn theo hướng cụ thể hóa các thông tư hướng dẫn chế độ kế toán dựa trên các chuẩn mực kế toán của Việt Nam (VAS) do Bộ tài chính ban hành và đa phần được thiết kế thành các học phần lý thuyết. Tuy nhiên, trong quá trình hội nhập kinh tế quốc tế, nhiều quốc gia trên thế giới đã áp dụng chuẩn mực Báo cáo tài chính quốc tế (IFRS) chính vì vậy Việt Nam không có con đường nào khác là phải tiếp cận, tiến tới áp dụng IFRS. Tại Hội thảo "IFRS-Định hướng và lộ trình áp dụng tại Việt Nam" do Bộ tài chính tổ chức, hầu hết các đại biểu là đại diện các doanh nghiệp, các trường đại học, uỷ ban chứng khoán nhà nước và các cơ quan có liên quan đều thống nhất cao bốn nội dung sau: (1) Áp dụng IFRS đầy đủ qua việc dịch trực tiếp IFRS và ban hành các thông tư hướng dẫn. (2) Lộ trình áp dụng theo từng đợt, mỗi đợt một số chuẩn mực và có hiệu lực đồng bộ. (3)Phạm vi áp dụng tại các công ty đại chúng trước, sau đó sẽ áp dụng dần dần cho toàn bộ các doanh nghiệp. (4) Thời điểm áp dụng từ năm 2020 trở đi.

Về phương pháp giảng dạy môn học này phổ biến hiện nay là các phương pháp truyền thống, thiên về các kỹ thuật ghi nhận các nghiệp vụ kinh tế phát sinh vào chứng từ, sổ sách kế toán, chưa phát huy được khả năng tư duy phản biện và tính sáng tạo của người học.

Như vậy, vấn đề cấp thiết đặt ra hiện nay cho các trường đại học có đào tạo ngành kế toán là phải đổi mới nội dung và phương pháp giảng dạy môn học Kế toán tài chính để cung cấp nguồn nhân lực kế toán có chất lượng đáp ứng được nhu cầu xã hội và hội nhập quốc tế.

\section{PHƯƠNG PHÁP NGHIÊN CỨU}

Tổng hợp kết quả của các nghiên cứu của các tác giả trước đó, nghiên cứu lý thuyết, quan sát thực tế khách quan từ đó đưa ra một số đề xuất nhằm giúp các trường đại học Việt Nam có những định hướng rõ ràng hơn trong quá trình đổi mới nội dung và phương pháp giảng dạy môn học môn học Kế toán tài chính trong các trường đại học Việt Nam hiện nay.

\section{THỰC TRẠNG ÁP DỤNG IFRS HIỆN NAY}

\section{Tóm lược các quốc gia, vùng lãnh thổ áp dụng IFRS trên thế giới}

Hiện nay IFRS đang ngày càng được áp dụng rộng rãi tại nhiều nước trên thế giới. Theo tài liệu của Ủy ban chuẩn mực kế toán quốc tế, đến năm 2016 đã có $131 / 143$ quốc gia và vùng lãnh thổ (chiếm tỷ lệ 93\%) đã tuyên bố chính thức về việc áp dụng với các hình thức khác nhau. Trong đó, có 119/143 (chiếm tỷ lệ $83,2 \%$ ) quốc gia và vùng lãnh thổ đã yêu cầu bắt buộc sử dụng các chuẩn mực của IFRS đối với tất cả hoặc hầu hết các công ty đại chúng trong nước. Theo báo cáo của Vụ Chế độ kế toán và kiểm toán, Bộ Tài chính tại hội thảo khoa học được tổ chức tại trường đại học Công Nghiệp thành phố Hồ Chí Minh vào tháng 6/2017, tình hình áp dụng IFRS trên thế giới được nêu trong bảng sau:

Ô màu đậm: Bắt buộc áp dụng đối với các đơn vị có lợi ích công chúng (119 quốc gia).

Ô màu nhạt: Cho phép lựa chọn áp dụng (12 quốc gia).

Ô màu trằng: Áp dụng chuẩn mực kế toán riêng của quốc gia (12), trong đó có một số nước cũng đã có kế hoạch để áp dụng IFRS (Thái Lan, Indonesia). 
TẠI CÁC TRƯỜNG ĐẠI HỌC VIỆT NAM TRONG XU THẾ HộI NHẬP QUỐC TẾ

Bảng 1. Tình hình áp dụng IFRS của các nước trên thế giới

\begin{tabular}{|c|c|c|c|c|c|}
\hline Átghanistan & Bulgaila & Germany & Latvia & Oman & StVincent and the Girenadines \\
\hline Albania & Cambodia & Chana & Lesotho & Palistan & Suriname \\
\hline Angola & Canada & Greecere & Liechtenstin & Palesine & Swaziland \\
\hline Angilla & Qaz/nan latenos & Gren:ada & Lithuania & Pallanla & Sweden \\
\hline Aniligua and Barbuda & Chile & Guatenal: & Luxembourg & Paligoliay & Svilzeland \\
\hline Argentihina & China & Gunnea-Bissau & Macao & Peru & Syia \\
\hline Amenia & Colombia & Gujana & Macedonia & Prilippines & Taiven \\
\hline Australlia & Costa Pilica & Hondures & Madiagesear & Poland & Tanzania \\
\hline$\overline{\text { Austria }}$ & Croalia & HongKong & Malasia & Portugal & Thailand \\
\hline$\overline{\text { Azendaian }}$ & Cypros & Hungaly & Maldives & Qatar & Tinididad and Tobago \\
\hline Bahamas & Gzech Republic & leveland & Malta & Romenila & Tukikey \\
\hline Barrain & Denmalk & noda & Mauritivs & Russia & Uganda \\
\hline Bangladesh & Dominiva & Indonesia & Merico & Rwanda & Ukiane \\
\hline Babados & Dominican Republic & liaq & Moddova & Saint Lucia & United Areb Eniviates \\
\hline Begium & Evadidor & lieland & Mongolla & Saudi Aabiab & United Kingdom \\
\hline Belans & Egypt & |sirel & Montsental & Setbia & United Stales \\
\hline Belize & El Salvador & |laly & Myannal & Sierra Leone & Uniglay \\
\hline Beminda & Estoria & Jamiaca & Nepal & Singapore & Uzbekistan \\
\hline Bhten & European Union & Japan & Netherlands & Slovakia & Venezula \\
\hline Bolivia & Fiii & Jordan & New Zealand & Slovenia & Vietnam \\
\hline Bosia and Herzegovina & Finland & Kenja & Nimeagra & South Alitia & Yemen \\
\hline Bolswana & Fience & Korea (Soutit) & Niger & Spain & Zambia \\
\hline Brazi| & Gambia & Kosovo & Nigeria & Siltanka & Zimbabwe \\
\hline Bunel & Georgia & Kuwat & Noway & StKitts and Neris & \\
\hline
\end{tabular}

Nguồn: trích dẫn tù bài hội thảo của Vu Chế độ kế toán và kiểm toán, Bộ Tài chính, 2017

\section{Lọi ích, khó khăn, thách thức khi áp dụng IFRS}

Bộ Tài chính đã khẳng định vai trò và lợi ích của việc áp dụng IFRS: "Không thể phủ nhận những lợi ích to lớn mà IFRS mang lại. Khi áp dụng IFRS, chất lượng của báo cáo tài chính của doanh nghiệp sẽ được cải thiện một cách rõ rệt thông qua việc nâng cao trách nhiệm giải trình, tăng cường tính minh bạch và khả năng so sánh, cung cấp cho người sử dụng báo cáo tài chính nhiều thông tin hữu ích cho việc ra quyết định quản lý, điều hành và đầu tư" (Vụ Chế độ kế toán và kiểm toán, Bộ Tài chính, 2017). Thấy được tầm quan trọng của việc áp dung IFRS đối với các tổ chức kinh tế trong việc lập và trình bày báo cáo tài chính nên Bộ tài chính đưa ra lộ trình áp dụng IFRS cho các doanh nghiệp Việt Nam. Theo đó dự kiến đến 2020, Chuẩn mực kế toán Việt Nam phải được ban hành lại và ban hành mới trên cơ sở cập nhật những thay đổi của Chuẩn mực quốc tế. Ngoài ra, các đơn vị có lợi ích công chúng sẽ phải dần chuyển đổi từ VAS/VFRS sang IFRS và đến 2025 phải hoàn tất quá trình chuyển đổi.

\section{LỢI ÍCH, KHÓ KHĂN, Lộ TRÌNH ÁP DỤNG IFRS VÀ BIỆN PHÁP THỰC HIỆN CỦA VIÊT NAM}

Theo Vụ Chế độ kế toán và kiểm toán, Bộ Tài chính, khi Việt Nam áp dụng IFRS có những thuận lợi và khó khăn thách thức như sau: 


\section{Về lọi ích}

- Yêu cầu tăng cường trách nhiệm giải trình, nâng cao tính minh bạch của Báo cáo tài chính và khả năng so sánh giữa các doanh nghiệp với nhau cũng như trong các giai đoạn khác nhau của cùng một doanh nghiệp. IFRS yêu cầu các giao dịch phải được phản ánh theo bản chất, phù hợp với cách thức vận hành hơn là tên gọi hay hình thức pháp lý của chúng, điều này sẽ giúp cho kết quả hoạt động kinh doanh của doanh nghiệp được phản ánh khách quan, trung thực.

- Giúp cung cấp cho người sử dụng báo cáo tài chính nhiều thông tin hữu ích cho việc ra quyết định quản lý, điều hành, quản trị và kiểm soát rủi ro.

- Là một yếu tố để quốc tế công nhận Việt Nam là một nền kinh tế thị trường đầy đủ, từ đó khơi thông dòng vốn FDI, thể hiện cam kết mạnh mẽ của Chính phủ trong việc bảo vệ các nhà đầu tư và tạo dựng môi trường kinh doanh lành mạnh phục vụ mục tiêu phát triển bền vững.

\section{Về khó khăn, thách thức}

- Thị trường vốn, thị trường tài chính chưa phát triển đủ mạnh, một số công cụ tài chính như trái phiếu chuyển đổi, công cụ phái sinh, cổ phiếu ưu đãi chưa được giao dịch rộng rãi nên hầu hết các doanh nghiệp chưa có kinh nghiệm trong việc thực hiện giao dịch và hạch toán các nội dung kinh tế liên quan.

- Nền kinh tế còn chịu ảnh hưởng lớn từ các doanh nghiệp Nhà nước mà các doanh nghiệp này khó có thể áp dụng và đáp ứng yêu cầu của IFRS do tâm lý sợ minh bạch, muốn giấu diếm sự thật về sức khỏe tài chính, muốn làm đẹp Báo cáo tài chính vì mục đích để được phân loại hoàn thành nhiệm vụ và giữ ghế Ban Lãnh đạo. Mặt khác, nhiều đoanh nghiệp Nhà nước là công ty mẹ của các đơn vị có lợi ích công chúng, nếu công ty con áp dụng IFRS trong khi công ty mẹ không áp dụng IFRS thì chính sách kế toán của tập đoàn không thống nhất và không thể thực hiện việc hợp nhất Báo cáo tài chính.

- Nguồn nhân lực nhìn chung chưa được đào tạo về IFRS, thiếu các chuyên gia có kinh nghiệm trong việc thực hành IFRS.

- IFRS yêu cầu một số kỹ thuật phức tạp và thực hiện một số đánh giá mang tính chủ quan, như việc thực hiện các ước tính về giá trị hợp lý khi không có giá niêm yết trên thị trường, giá trị có thể thu hồi, tổn thất tài sản của đơn vị tạo tiền và lợi thế thương mại, xác định giá trị hiện tại của dòng tiền tương lai... nên về cơ bản IFRS chỉ phù hợp với những doanh nghiệp có quy mô lớn, công tác kế toán được thực hiện bài bản, nề nếp. Qua khảo sát cho thấy, các quốc gia trên thế giới thường chỉ bắt buộc các đơn vị có lợi ích công chúng áp dụng nguyên mẫu IFRS còn các doanh nghiệp khác chỉ khuyến khích vì có thể không có đủ nguồn lực cần thiêt.

- Rào cản ngôn ngữ cũng là một khó khăn cần tính đến do IFRS được soạn thảo bằng tiếng Anh và để có thể phổ biến, quảng bá rộng rãi IFRS đến công chúng, cần phải dịch sang tiếng Việt. Tuy nhiên việc chuyển tải chính xác các thuật ngữ chuyên môn không phải là điều dễ dàng vì người có đủ trình độ ngoại ngữ lại chưa chắc có đủ trình độ chuyên môn và ngược lại. Mặt khác, khi xảy ra tranh chấp giữa doanh nghiệp và kiểm toán, thanh tra..., rào cản ngôn ngữ sẽ là một trong những nguyên nhân gây tranh cãi nhiều nhất.

- Trong nội tại cơ quan quản lý Nhà nước còn nhiều ý kiến cho rằng do IFRS yêu cầu phải đánh giá lại nhiều loại tài sản và nợ phải trả theo giá trị hợp lý, giá trị có thể thu hồi... nên rất khó kiểm tra, kiểm soát, đặc biệt làm cho việc xác định thu nhập chịu thuế trở nên phức tạp hơn do khoảng cách giữa thu nhập chịu thuế và lợi nhuận kế toán có thể càng ngày càng khác biệt.

\section{Về lộ trình áp dụng IFRS và biện pháp thục hiện của Việt Nam}

Cũng theo Vụ Chế độ kế toán và kiểm toán, Bộ Tài chính, trong trường hợp tuyên bố tuân thủ và áp dụng IFRS tại Việt nam, Việt Nam phải xây dựng lộ trình cụ thể áp dụng IFRS. Dự kiến những công việc chủ yếu phải thực hiện theo từng giai đoạn như sau:

\section{- Giai đoạn 2017-2018:}

+ Tổ chức các hoạt động nghiên cứu, hội thảo lấy ý kiến của các chuyên gia, doanh nghiệp, trường đại học về các nội dung dự thảo VAS/VFRS và IFRS,

+ Đào tạo, dịch tài liệu về IFRS;

+ Khảo sát sự sẵn sàng áp dụng IFRS tại các đơn vị có lợi ích công chúng;

+ Đánh giá tác động của việc áp dụng IFRS. Đánh giá các khác biệt về cơ chế tài chính của Việt Nam với IFRS; 
+ Lựa chọn một số đơn vị áp dụng thí điểm IFRS;

- Giai đoạn 2018-2020:

+ Lựa chọn một số IFRS (khoảng từ 10-20 IFRS) đơn giản phù hợp với điều kiện thực tiễn Việt Nam và công bố tuân thủ, áp dụng đối với tất cả các đơn vị có lợi ích công chúng từ năm 2020; Các đơn vị được lựa chọn thí điểm áp dụng từ 2019;

+ Xây dựng hướng dẫn áp dụng IFRS;

+ Tiếp tục tuyên truyền, quảng bá, đào tạo IFRS cho các doanh nghiệp, công ty kiểm toán, trường đại học;

- Giai đoạn 2020 đến 2021:

+ Tiếp tục công bố, tuân thủ thêm một số IFRS (dự kiến nâng số lượng IFRS được tuân thủ lên 30 Chuẩn mực)

+ Khuyến khích các đơn vị không có lợi ích công chúng nhưng có đủ điều kiện và mong muốn được lập và trình bày Báo cáo tài chính theo IFRS;

+ Tiếp tục xây dựng hướng dẫn áp dụng IFRS; đào tạo IFRS

+ Tiếp tục hỗ trợ các doanh nghiệp trong việc triển khai áp dụng, các trường đại học trong việc

- Giai đoạn 2021-2022:

+ Tuyên bố tuân thủ hoàn toàn IFRS;

+ Tiểp tục hỗ trợ các doanh nghiệp và trường đại học, xây dựng hoàn chỉnh bộ hướng dẫn áp dụng IFRS và sửa đổi, bổ sung, cập nhật hàng năm theo sự thay đổi của quốc tế.

\section{THỰC TRẠNG GIẢNG DẠY MÔN HỌC KẾ TOÁN TÀI CHÍNH TRONG CÁC TRƯ Ờ G ĐẠI HỌC VIẸT NAM HIỆN NAY}

\section{Về nội dung môn học Kế toán tài chính}

Nhà trường nên thực hiện phương châm đào tạo những gì xã hội cần hơn là đào tạo cái mình có, hãy chấm dứt phương pháp đào tạo theo kiểu "tầm câu trích cú", đừng để sinh viên kế toán trở thành những con robot vì chỉ thuộc lòng lý thuyết mà không biết vận dụng lý thuyết vào thực tiễn (Vụ Chế độ kế toán và kiểm toán, Bộ Tài chính, 2017). Việt Nam đang hội nhập kinh tế quốc tế, việc đào tạo kế toán tài chính của các trường đại học theo những nội dung và phương pháp hiện nay chưa đáp ứng được yêu cầu hội nhập quốc tế. Nhóm tác giả khảo sát giáo trình và đề cương dùng để giảng dạy môn Kế toán tài chính của một số trường Đại học ở thành phố Hồ Chí Minh có đào tạo chuyên ngành kế toán. Kết quả khảo sát cho thấy:

Đa số các trường đại học hiện nay biên soạn nội dung môn học Kế toán tài chính theo thông tư hướng dẫn chế độ kế toán doanh nghiệp số 200/2014 ban hành ngày 22/12/2014 của Bộ Tài chính. Nội dung chính của các giáo trình này thường là giới thiệu các chứng từ, tài khoản, sổ kế toán sử dụng, phương pháp ghi nhận các nghiệp vụ kinh tế phát sinh chủ yếu và trình bày thông tin trên Báo cáo tài chính. Nội dung môn học được thiết kế dựa trên Chế độ kế toán do Bộ tài chính ban hành, tập trung quá nhiều vào hướng dẫn nghiệp cụ kế toán mà chưa chú trọng đến những vấn đề nền tảng, các chuẩn mực nghề nghiệp. Chính vì biên soạn theo thông tư, chế độ nên việc giảng dạy theo chi tiết các bút toán kế toán. Tuy nhiên các bút toán quy định trong thông tư, chế độ chỉ là các bút toán của một số giao dịch kinh tế và cho dù có chi tiết hơn nữa cũng thể bao quát được toàn bộ các giao dịch kinh tế phát sinh trong đời sống kinh tế xã hội. Cũng theo Bộ Tài Chính, trong tương lai, khi ban hành lại các Chuẩn mực kế toán Việt Nam theo định hướng IFRS, Bộ Tài chính dự kiến sẽ không quy định Chế độ kế toán chi tiết như hiện nay mà thay vào đó là ban hành bộ hướng dẫn áp dụng Chuẩn mực kế toán. Các bút toán định khoản quy định cứng nhắc như hiện nay sẽ không còn mang tính bắt buộc mà chỉ mang tính hướng dẫn, tham khảo, việc lập các bút toán hầu như đơn thuần là nhập dữ liệu và chỉ đóng vai trò thứ yếu trong công tác kế toán.

Theo nhiều tác giả đã nghiên cứu việc đào tạo kế toán hiện nay đang thực hiện đơn thuần theo hướng đưa ra cách thức phải làm như thế nào một cách cứng nhắc mà không cho người ta biết vì sao phải làm như vậy. Người học nếu chỉ được truyền thụ về cách làm thì sẽ bị triệt tiêu mất sự sáng tạo. Đào tạo ngành kế toán của các trường đại học ở Việt Nam vẫn còn tồn tại nhiều bất cập, khoảng cách kỳ vọng của các nhà tuyển dụng và sinh viên tốt nghiệp còn khá lớn, số lượng sinh viên ra trường làm không đúng ngành hoặc không 
có việc làm có xu hướng gia tăng. Nội dung các môn học còn nặng về lý thuyết thuần túy, quá ít giờ thực hành và giờ tự học của sinh viên. (Đặng Đức Sơn, 2013, Vụ Chế độ kế toán và kiểm toán, Bộ Tài chính 2017, Đường Thị Quỳnh Liên, 2017).

Ngoài ra nội dung Kế toán tài chính đào tạo theo VAS cũng rất lạc hậu. Đã hơn 10 năm qua VAS chưa được cập nhật, bổ sung vì thế no trở lên lỗi thời trong khi IFRS luồn hiệu chỉnh, bổ sung nhiều IFRS mới, thay thế cho các IAS cũ không còn hiệu lực. Ngoài ra, do những thay đổi về bối cảnh kinh tế toàn cầu nên nhiều vấn đề mới trong kế toán cũng đã xuất hiện, trong khi hơn 10 năm qua chúng ta không ban hành một chuẩn mực kế toán mới nào, mà chỉ là sự thay đổi về chế độ kế toán. Cũng theo Vụ Chế độ kế toán và kiểm toán, Bộ Tài chính, phần lớn sinh viên tốt nghiệp từ các trường đại học chưa được trang bị những kiến thức cơ bản về IFRS do hầu hết các trường đại học chưa giảng dạy cả về mặt nội dung cũng như phương pháp nghiên cứu IFRS.

Việc biên soạn và đưa nội dung IFRS vào giảng dạy trong một số ít các trường mới dừng ở những bước khởi đầu. Đa số các trường thiết kế nội môn học kế toán tài chính chỉ bao gồm các nội dung theo VAS, còn IFRS được biên soạn và giảng dạy trong môn học Kế toán quốc tế, như Đại học Kinh tế TP HCM, Đại học Công nghiệp TP HCM,... Tuy nhiên nội dung giảng dạy IFRS cũng chỉ dừng lại ở một số chuẩn mực phổ biến.

Trước yêu cầu hội nhập kinh tế, hội nhập kế toán, và lộ trình, định hướng của Bộ Tài Chính về việc áp dụng IFRS thì nội dung môn học kế toán tài chính đang giảng dạy ở các trường đại học Việt Nam hiện nay còn nhiều bất cập và lỗi thời. Để dạt được mục tiêu hội nhập và vận dụng được IFRS, các trường đại học cần phải biên soạn nội dung môn học Kế toán tài chính cho phù hợp với lộ trình áp dụng IFRS cần phải được tiến hành ngay từ bây giờ để đến năm 2020, các trường đại học có thể cung cấp một lượng sinh viên tốt nghiệp đáp ứng nhu cầu xã hội về nguồn nhân lực kế toán.

\section{Vè̀ phương pháp giảng dạy môn học Kế toán tài chính}

Phương pháp giảng dạy môn học Kế toán tài chính thường được giảng viên các trường đại học áp dụng là phương pháp thuyết giảng. Giảng viên chủ yếu trình bày các nội dung chính như các nguyên tắc hạch toán, phương pháp ghi nhận các nghiệp vụ phát sinh vào chứng từ, sổ kế toán và trình bày thông tin trên các chỉ tiêu liên quan trên Báo cáo tài chính. Phương pháp giảng dạy cổ điển vẫn đóng vai trò chủ đạo trong giảng dạy. Chính vì vậy mà tác giả Trương Thanh Hằng, Nguyễn La Soa 2017, Nguyễn Thị Mai Hương, 2017 đã nói phương pháp giảng dạy "thầy đọc, trò chép và làm bài tập" trước kia nay được thay bằng công thức "thầy giảng, trò nghe và làm bài tập". Cách làm này tưởng chừng như đã đồi mới phương pháp dạy học nhưng không đảm bảo được tinh thần khuyến khích người học phải làm việc và không đảm bảo nâng cao kiển thức cho người học ở trình độ cao, người học chỉ học được những gì thậy dạy.

Kế toán tài chính, không chỉ là Nợ - Có, mà Kế toán tài chính thực sự là một môn khoa học nên việc đào tạo người làm kế toán trước tiên cần cung cấp cho họ phương pháp tư duy, phương pháp luận giải xử lý vấn đề hơn là bắt họ học thuộc lòng những bút toán định khoản khô khan. Theo nhiều nghiên cứu trên thế giới chỉ ra rằng, sinh viên hiện nay học nhiều hơn, tiếp thu nhiều hơn và thành công hơn khi được tiếp cận với các phương pháp học tập chủ động thay vì các phương pháp học tập thụ động, truyền thống (Bonwell và Eison, 1991; Meyers và Jonh, 1993; Raux, 2004). Học tập chủ động mang đến những cơ hội cho sinh viên được diễn giải, lắng nghe, thể hiện khả năng đọc, viết và phản ánh những nội dung, ý tưởng, vấn đề, khái niệm của một môn học. (Meyers và Jones, 1993). Theo Braun và Sellers (2012), vai trò quan trọng của giảng viên dạy kế toán ngoài việc cung cấp cho sinh viên những kiến thức và kỹ năng nghề nghiệp kế toán thì còn phải dạy các em sinh viên những kỹ năng giao tiếp, đạo đức nghề nghiệp và khả năng ứng xử thích hợp và chuyên nghiệp trong từng tình huống. Theo Luật giáo dục, yêu cầu về phương pháp đào tạo trình độ đại học là "phải coi trọng việc bồi dưỡng ý thức tự giác trong học tập, năng lực tự học, tự nghiên cứu, phát triển tư duy sáng tạo, rèn luyện kỹ năng thực hành, tạo điều kiện cho người học tham gia nghiên cứu, thực nghiệm, ứng dụng”.

Chính vì vậy tác giả Trần Hồng Vân, Dương Hoàng Ngọc Khuê, 2017 cũng đã nói phương pháp giảng dạy cần phải điều chỉnh theo hướng tiếp cận các nguyên tắc đồng thời kết hợp các phương pháp giải huống thực tế tại Việt Nam để sinh viên vừa có hiểu biết về IFRS vừa có thể vận dụng xử lý theo quy trình kế toán của Việt Nam.

Theo quan sát của nhóm tác giả ở một số trường đại học ở thành phố Hồ Chí Minh, các giảng viên 
cũng thường xuyên hỏi đáp sinh viên trong quá trình diễn giảng, cho ví dụ minh họa, ra bài tập trên lớp, bài tập về nhà, yêu cầu sinh viên thực hiện các ví dụ, bài tập theo nhóm hoặc từng cá nhân trên cơ sở vận dụng các lý thuyết đã học. Tuy nhiên tần suất giao tiếp giữa giảng viên và sinh viên còn ít và chưa có cơ chế kiểm tra, kiểm soát các công việc giao cho sinh viên.

Thông qua những quan sát mà nhóm tác giả ghi nhận được, cùng với các nghiên cứu của các tác giả trước đây có thể kết luận hiện nay hầu hết các trường vẫn sử dụng phương pháp truyền thống trong giảng dạy kế toán. Giảng viên hiện nay cũng có thay đổi, cải tiến phương pháp giảng dạy nhưng nhìn chung là chưa thoát khỏi bản chất của phương pháp giảng dạy truyền thống.

\section{GIẢI PHÁP ĐỔI MỚI NộI DUNG VÀ PHƯƠNG PHÁP GIẢNG DẠY MÔN HỌC KẾ TOÁN TÀI CHÍNH}

\section{Đổi mới nội dung môn học Kế toán tài chính}

Kế toán tài chính là môn học trang bị cho người học kế toán những kiến thức, kỹ năng nghề nghiệp đảm bảo cho người học làm được kế toán tại các đơn vị trong và ngoài nước. Trong thời kỳ hội nhập kinh tế hiện nay, nên nội dung môn học Kế toán tài chính đòi hỏi phải đáp ứng được những yêu cầu cung cấp thông tin kinh tế, tài chính minh bạch cho người sử dụng. Theo như bài báo đã phân tích ở trên, nội dung giảng dạy môn học Kế toán tài chính ở các trường đại học ở nước ta hiện nay còn nhiều bất cập và chưa hội tụ với các nước trong khu vực và thế giới. Chính vì vậy nội dung môn học này cần phải được biên soạn và giảng dạy trong nhà trường theo các định hướng sau:

- Tập trung vào những nguyên tắc kế toán theo cách tiếp cận của IFRS, theo đó, mục tiêu cuối cùng của kế toán tài chính là Báo cáo tài chính phải được lập ra một cách đúng đắn nhất nhằm cung cấp những thông tin minh bạch, trung thực và hợp lý đáp ứng nhu cầu của người sử dụng. Các kỹ thuật ghi nhận trên chứng từ, sổ sách kế toán chỉ là những công cụ mà người làm kế toán thực hiện để có được sản phẩm của mình mà thôi. Vấn đề cốt lõi là sinh viên phải phân tích và giải thích được bản chất của nghiệp vụ kinh tế phát sinh, từ đó mới có thể trình bày trung thực và hợp lý thông tin mà nghiệp vụ đó phản ánh trên báo cáo tài chính. Vì vậy, nhiều ví dụ, nhiều tình huống thực tế cần được đưa vào nội dung của môn học để hướng dẫn và giải thích rõ ràng cho những nguyên tắc kế toán được đưa ra.

- Trong giai đoạn đầu của lộ trình áp dụng IFRS, nội dung môn học cần trình bày song song cả VAS và IFRS dưới dạng phân tích, so sánh những điểm giống và khác nhau giữa VAS và IFRS, đồng thời giải thích sự khác biệt một cách rõ ràng thông qua các ví dụ, các tình huống thực tế.

- Những nội dung IFRS được biên soạn trong môn học Kế toán tài chính nên được trình bày song ngữ để sinh viên được tiếp cận với phiên bản gốc của IFRS, từ đó nâng cao năng lực sử dụng các thuật ngữ chuyên ngành bằng tiếng Anh, tiến tới việc các em có thể tự đọc hiểu và vận dụng IFRS mỗi khi có sự thay đổi, cập nhật mới.

- Tích hợp cả lý thuyết và thực hành trong mỗi học phần của môn học. Ví dụ môn học Kế toán tài chính có thể chia thành 4 học phần, mỗi học phần 3 tín chỉ trong đó có 2 tín chỉ lý thuyết và 1 tín chỉ thực hành. Nội dung thực hành là những công việc, những tình huống kế toán thực tế có thể được hướng dẫn trên lớp học lý thuyết hoặc trên phòng thực hành mô phỏng (mô phỏng lại công việc kế toán trong một đơn vị cụ thể để sinh viên được đóng vai là những nhân viên kế toán thực thụ) và tại các đơn vị thực tế.

- Các nội dung thực hành trong môn học không chỉ tập trung vào kỹ năng nghề nghiệp mà còn phải chú trọng đến việc rèn luyện cho sinh viên kỹ năng giao tiếp bằng lời nói, văn bản, ngôn ngữ cơ thể, những vẩn đề liên quan đến đạo đức nghề nghiệp, thái độ ứng xử hợp lý, tác phong làm việc chuyên nghiệp trong từng tình huống thực tế.

Các đề xuất trên của nhóm tác giả đã góp phần cũng cố thêm ý kiến của các tác giả nghiên cứu trước đây, như theo tác giả Trần Hồng Vân, Dương Hoàng Ngọc Khuê, 2017 khuyến nghị về việc đào tạo IFRS tại Việt Nam theo hướng tích hợp IFRS trong chương trình đào tạo: đối với những sinh viên ngoài ngành kế toán cần phải trang bị những kiến thức tổng quát về IFRS ở những năm đầu của chương trình đào tạo. Nội dung môn học Nguyên lý Kế toán cần được thay đổi theo hướng tiếp cận theo nguyên tắc, bản chất, khái niệm hơn là các phương pháp hạch toán kế toán. Đối với sinh viên chuyên ngành kế toán, cần phải được trang bị IFRS trên toàn bộ chương trình đào tạo để sinh viên có được một sự hiểu biết tốt hơn và đánh giá cao của sự khác biệt quan trọng giữa các hệ thống báo cáo tài chính được lập dựa trên nguyên tắc và dựa trên quy định, giúp cho sinh viên chuyên ngành kế toán đánh giá tốt hơn về tác động của IFRS 
và VAS trên nhiều lĩnh vực kế toán.

Việc áp dụng IFRS sẽ có nhiều lợi ích như nâng cao mức độ tin cậy của thông tin đối với nhà đầu tư, cho phép so sánh thông tin giữa các doanh nghiệp trong nước và các quốc gia, tạo điều kiện thuận lợi để tiếp cận với các nguồn đầu tư nước ngoài, làm cho môi trường kinh doanh của Việt Nam tốt hơn. Tuy nhiên cần phải có sự chuẩn bị và hành động một cách đồng bộ giữa Bộ Tài chính, các tổ chức nghề nghiệp, các trường đại học và các trung tâm đào tạo thì đề án áp dụng IFRS tại Việt Nam mới thành công.

\section{Đổi mới phuơng pháp giảng dạy Kế toán tài chính}

Việc đổi mới nội dung môn học Kế toán tài chính phải được thực hiện song song với đổi mới phương pháp giảng dạy nhằm giúp sinh viên có thể đạt được chuẩn đầu ra của môn học một cách dễ dàng. Do cách tiếp cận hướng đến việc trình bày thông tin hữu ích trên Báo cáo tài chính nên phương pháp giảng dạy không nên tập trung vào việc thuyết trình, diễn giải các kỹ thuật ghi nhận số liệu kế toán.

Chuyển đổi từ phương pháp giảng dạy truyền thống sang phương pháp giảng dạy tích cực, lấy người học làm trung tâm, phát huy tính chủ động của sinh viên phải được áp dụng triệt để nhằm hướng sinh viên vào việc vận dụng những nguyên tắc kế toán, nâng cao kỹ năng phán xét nghề nghiệp để giải quyết các vấn đề thực tế. Theo nhóm tác giả các phương pháp giảng dạy phải đạt được mục tiêu sau:

Hiểu lý thuyết IFRS $\rightarrow$ Vận dụng thuyết IFRS vào bài tập $\rightarrow$ Áp dụng IFRS vào các tình huống cụ thể $\rightarrow$ Úng dụng IFRS trong thực tế

Chính vì vậy nhóm tác giả đề xuất một số phương pháp dạy học tích cực phù hợp với việc giảng dạy giảng dạy môn học Kế toán tài chính theo hướng áp dụng IFRS.

\section{- Thuyết giảng tuoong tác}

Thuyết giảng là phương pháp giảng dạy truyền thống, tuy nhiên, không một quá trình dạy học hiện đại nào lại có thể bỏ qua phương pháp này. Giảng viên hạn chế việc nói suốt buổi học vì đó là thuyết giảng một chiều, là phương pháp giảng dạy thụ động, nó không đem lại cơ hội cho sinh viên tương tác với giảng viên vì vậy nó không phù hợp cho việc giảng dạy các nội dung theo IFRS. Trong quá trình giảng dạy kế toán tài chính theo hướng áp dụng IFRS, việc diễn giải những nguyên tắc, khái niệm của kế toán cần được thực hiện theo lối tương tác, đặt vấn đề để sinh viên được động não và được lôi cuốn vào quá trình giải quyết vấn đề cùng với giảng viên. Phương pháp này giúp sinh viên có nhiều cơ hội trao đổi với giảng viên để hiểu rõ hơn về bản chất của kế toán tài chính theo hướng áp dụng IFRS.

\section{- Giảng day dựa trên vấn đề}

Khởi đầu của toàn bộ thông tin kinh tế tài chính mà kế toán cung cấp chính là các hoạt động của đơn vị kế toán. Những hoạt động này rất đa dạng, biến động không ngừng, và đây chính là các vấn đề cần được đưa ra để người học được trải nghiệm những cách thức giải quyết vấn đề, từ đó tiếp nhận kiến thức một cách tự nhiên nhất, dễ dàng nhất. Kế toán áp dụng theo IFRS, người làm kế toán tự quyết định việc ghi nhận các nghiệp vụ kinh tế phát vào sổ sách kế toán và lập báo cáo tài chính. Không có hướng dẫn cụ thể như các thông tư hiện nay của Việt Nam. Vì vậy việc dạy cho sinh viên tự nhận dạng các vấn đề kinh tế để quyết định ghi chép kế toán là điều rất cần thiết và mang tính đổi mới hiện nay. Để phát huy hiệu quả của phương pháp này giảng viên nên tổ chức cho sinh viên hoạt động theo nhóm và mỗi cá nhân sẽ hợp tác với nhóm để tìm ra cách giải quyết vấn đề tối ưu nhất, qua đó, sinh viên được tiếp cận được kiến thức cốt lõi của IFRS và áp dụng chúng vào bài tập và tình huống thực tiễn, từ đó phát triển khả năng tư duy độc lập, năng lực phát hiện và giải quyết vấn đề của sinh viên.

\section{- Giảng dạy lấy nguời học làm trung tâm}

Phương pháp này cũng rất phù hợp cho việc đào tạo kế toán theo hướng áp dụng IFRS. Giảng viên là người hướng dẫn, sinh viên là trung tâm của việc học. Sinh viên chủ động nêu ý kiến của mình và từ đó quá trình giảng dạy sẽ sát với nhu cầu của sinh viên hơn trong việc tìm hiểu IFRS. Giảng viên nên kết hợp phương pháp này với các kỹ thuật dạy học như đóng vai, động não, làm việc nhóm,... sẽ giúp sinh viên chủ động lĩnh hội tri thức về IFRS dưới sự hướng dẫn của giảng viên. Đối với môn học kế toán tài chính theo hướng áp dụng IFRS, mỗi nguyên tắc kế toán, mỗi chỉ tiêu cần trình bày trên báo cáo tài chính, đều có thể là những nội dung để sinh viên chủ động lựa chọn, thảo luận và tìm ra bản chất của vấn đề. Giảng viên chỉ cần định hướng, dẫn dắt nhằm giúp sinh viên có thể tiếp thu hiệu quả nội dung cần truyền đạt. 


\section{- Giảng dạy theo tình huống}

Như đã trình bày ở các phương pháp trên, sinh viên phải áp dụng được nội dung của IFRS trong các tình huống cụ thể cũng như áp dụng được IFRS vào thực tiễn. Chính vì vậy phương pháp dạy theo tình huống rất phù hợp trong việc đào tạo IFRS. Giảng viên phải đưa vào bài giảng của mình những tình huống kế toán thực tế để sinh viên được tham gia vào giải quyết các tình huống này, điều này giúp sinh viên tiếp cận được thực tiễn nghề nghiệp ngay tại lớp học. Chính vì tính chất có thật của tình huống đã làm cho sinh viên chủ động, sáng tạo, hứng thú với bài học và từ đó tiếp cận và ứng dụng kế toán theo IFRS có hiệu quả.

Tất cả các phương pháp giảng dạy cho dù là phương pháp truyền thống hay phương pháp hiện đại đều cần phải điều chỉnh theo hướng tiếp cận các nguyên tắc của IFRS đồng thời kết hợp các phương pháp giải thích tình huống thực tế tại Việt Nam để sinh viên vừa có hiểu biết về IFRS vừa có thể vận dụng xử lý theo quy trình kế toán của Việt Nam. Cần kết hợp với đội ngũ kế toán, kiểm toán viên chuyên nghiệp đang công tác tại các công ty, tập đoàn lớn trong và ngoài nước có nhiều năm kinh nghiệp làm việc đến trao đổi các vấn đề thực tiễn, và giải đáp các vấn đề kế toán thực tế phát sinh cho sinh viên.

Ngoài ra các trường đại học có đào tạo chuyên ngành kế toán cũng cần chú ý đầu tư phương tiện học tập giảng dạy hiện đại cho sinh viên như E-learning, thành lập các câu lạc bộ kế toán, các tổ chức chuyên môn về kế toán để giúp các em có phương pháp tự học và có nơi trao đổi học hỏi và va chạm thực tế.

\section{KẾT LUẬN}

Đổi mới nội dung và phương pháp giảng dạy môn học Kế toán tài chính là một trong những vấn đề đáng quan tâm ở bất cứ trường đại học nào có đào tạo ngành kế toán tại Việt Nam. Để nâng cao chất lượng đào tạo ngành kế toán, nội dung môn học Kế toán tài chính cần phải được cập nhật, đổi mới theo hướng tiếp cận với hệ thống chuẩn mực Báo cáo tài chính quốc tế IFRS. Bên cạnh đó, các phương pháp giảng dạy tích cực như thuyết giảng, tương tác, giảng dạy dựa trên vấn đề, giảng dạy lấy người học làm trung tâm, giảng dạy theo tình huống, ... cũng cần phải được giảng viên khai thác, áp dụng rộng rãi.

\section{LÒ̀I CẢM ƠN}

Chúng tôi gởi lời cảm ơn chân thành tới các trường Đại học tại thành phố Hồ Chí Minh đã tạo điều kiện cho chúng tôi trong quá trình khảo sát và quan sát. Chúng tôi cũng gởi lời cảm ơn đến các đồng nghiệp và những người cộng tác với chúng tôi để hoàn thành bài nghiên cứu này. Sau cùng chúng tôi gởi lời cảm ơn đến tất cả các tác giả của các bài báo, các công trình nghiên cứu mà chúng tôi trích dẫn trong bài báo của chúng tôi.

\section{TÀI LIỆU THAM KHẢO}

[1] Frederick D. S. Choi , Gary K. Meek (2010), International Accounting (7th Edition), Pearson, p 5.

[2] Vụ Chế độ kế toán và kiểm toán, Bộ Tài chính, 2017. Phát triển và hoàn thiện khuôn khổ pháp lý về chuẩn mực báo cáo tài chính tại Việt Nam, Hội thảo khoa học, TP.HCM

[3] Đặng Đức Sơn, 2013. Những vấn đề nâng cao chất lượng nhân sự kế toán, kiểm toán ở Việt Nam. Kỷ yếu hội thảo Kế toán - Kiểm toán trong quá trình cải cách và hội nhập, 302-305.

[4] Bailey, D (1995), Accounting in Transition in the Transitional Economy, European Accounting Review, 4 (4): 595-623.

[5] Bonwell, C. C. and Eison, J. A., "Active Learning: Creating excitement in the classroom", ASHEERIC Higher Education Report No. 1, Washington D.C.: The George WashingtonUniversity, School of Education and Human Development, 1991.

[6] Braun, K. W. \& Sellers, R. D. (2012). Using a "Daily Motivational Quiz" to Increase Student Preparation, Attendance, and Participation. Issues in Accounting Education, 27(1), 267-279. 
[7] Meyers, C. and Jones T.B., Promoting Active Learning: Strategies for the College Classroom, Jossey-Bass Publishers, San Francisco, CA, 1993.

[8] Nguyễn Hữu Ánh, 2017. Đổi mới đào tạo ngành Kế toán của các trường Đại học ở Việt Nam đáp ứng yêu cầu xã hội trong xu thế hội nhập. Hội thảo khoa học, TP.HCM

[9] Nguyễn Thị Mai Hương, 2017. Đổi mới chương trình, nâng cao chất lượng đào tạo chuyên ngành Kế toán Kiểm toán đáp ứng yêu cầu hội nhập, Hội thảo khoa học, TP.HCM

[10] Raux, Donald J., "Implementing Active Learning in College Accounting Classes", Explorations in Teaching and Learning, Vol. 16, No. 1, Winter, 2004.

[11] Raux, Donald J., "Teaching an Effective Accounting Class in the 21st Century: Using ActiveLearning Techniques". European Journal of Management, Volume 9, Number 4, 2009.

[12] Đường Thị Quỳnh Liên, 2017. Khó khăn, thách thức trong việc tiếp cận đào tạo IFRS tại các trường Đại học Việt Nam, Hội thảo khoa học, TP.HCM

[13] Trương Thanh Hằng, Nguyễn La Soa, 2017. Đổi mới chương trình đào tạo Kế toán trong các trường Đại học Việt Nam - Nên tiếp cận theo nguyên tắc hay theo qui tắc, Hội thảo khoa học, TP.HCM

[14] Trần Hồng Vân, Dương Hoàng Ngọc Khuê, 2017. Tích hợp IFRS trong chương trình đào tạo ngành Kế toán, Hội thảo khoa học, TP.HCM

Ngày nhận bài: 14/08/2017

Ngày chấp nhận đăng: 21/11/2017 